\title{
An Oral English Evaluation Model Using Artificial Intelligence Method
}

\author{
Yawei Yu, Lu Han (D, Xueqin Du, and Jing Yu $(D)$ \\ School of Humanities, Jiangxi University of Chinese Medicine, Nanchang 330004, Jiangxi, China \\ Correspondence should be addressed to Jing Yu; zoe90826@163.com
}

Received 14 January 2022; Revised 8 February 2022; Accepted 9 February 2022; Published 7 March 2022

Academic Editor: Tongguang $\mathrm{Ni}$

Copyright (c) 2022 Yawei Yu et al. This is an open access article distributed under the Creative Commons Attribution License, which permits unrestricted use, distribution, and reproduction in any medium, provided the original work is properly cited.

\begin{abstract}
Despite the fact that oral English classes have been available since primary school, most students' oral English skills are poor and they struggle to communicate in simple everyday situations. This new requirement has been proposed in light of the general lack of English listening and speaking skills among Chinese college students. The current manual test for CET-4 and CET-6 will be gradually replaced by a computer test, and the CET-6 computer test will be included in the "quality engineering" project of national university teaching. The natural integration of artificial intelligence and education is assisting in the transformation of the traditional education ecology. Mind mapping has also had a significant impact on the education industry, and it has significant value in current educational applications. In order to truly realize personalized learning, we should pay more attention to the educational noumenon that the status of educators and learners has changed in education, that is, the transformation from educators to learners' development. Artificial intelligence technology can be used effectively by junior high school English teachers to conduct oral English evaluation activities, which can more accurately judge students' oral English expression ability and serve as a useful tool for adjusting and improving students' learning methods.
\end{abstract}

\section{Introduction}

The traditional teaching method means that teachers do not optimize the curriculum teaching in combination with mind map, but simply show the existence of mind map to students and do not deeply think about the different application methods of mind map in the curriculum. Although oral English courses have been offered since primary school, most students' oral English ability is not outstanding, and they cannot even cope with some simple daily communication [1]. At present, "College Students' Curriculum Requirements" also clearly puts forward that students' oral expression ability should be regarded as an important training goal of English. Oral English evaluation under artificial intelligence is a key course in junior high school, which is of positive significance for cultivating students' cross-language communicative competence $[2,3]$. Therefore, in English teaching, it is very important to effectively teach oral English and improve students' oral English level. Therefore, the English Curriculum Standard for Compulsory
Education states that students' oral English evaluation ability must be improved. CET-4 and CET-6, which are the main means to assess whether Chinese college students' English ability meets the "Teaching Requirements", are also being reformed accordingly. The way of CET-4 and CET- 6 will gradually change from the current manual test to the computer test, and CET-6 computer test will be included in the "quality engineering" project of national university teaching $[4,5]$. Under the background of artificial intelligence, teachers can actively use various technical means to solve the problems existing in the current oral English evaluation, change students' English learning concepts, optimize students' oral English evaluation methods, enhance students' oral English expression ability, and achieve the high-quality goal of oral English evaluation [6].

Artificial intelligence is the theory, method, and technology of using computer to simulate human intelligent behavior [7]. Oral English learning and practice are important parts of junior high school English learning. In language communication, middle school students can 
quickly grasp the learning points and constantly enhance their expression ability. With the support of oral English evaluation under artificial intelligence, oral English evaluation in junior middle school can realize real interactive teaching between human and computer and one-to-one teaching guidance between human and computer, which has changed the traditional teacher guidance mode, greatly improved English teaching and learning efficiency, and saved economic cost $[8,9]$. In the process of learning oral English evaluation, the completion of students' oral preview tasks, the selection and use of oral English evaluation resources, the quality of personal oral expression in oral communication activities, and the completion of afterschool review tasks are tracked, recorded, and evaluated by the artificial intelligence technology platform to form corresponding intelligent analysis results. Based on this, teachers make a formative evaluation of students' learning, pay attention to individual differences, suit the remedy to the case, and teach students according to their aptitude [10]. They explore new education modes and improve the quality of education and teaching.

Currently, "College Students' Curriculum Requirements" states unequivocally that students' oral expression ability should be considered an important English training goal [11]. Oral English instruction, as an important component of English instruction, is a key indicator of a student's true English ability. The most important value of a mind map in these fields is to assist human beings in developing a clear action process framework in the fields of life and study [12]. Mind mapping has also had a significant impact on the education industry, and it has significant value in today's educational environment. Our goal is to write a small ETL tool on our own for the data warehouse system of the college English examination and to set up a data mart quickly and easily, contents of learning, learning methods, and learning evaluation, among other things $[13,14]$. We pay more attention to the education noumenon, that is, the status of educators and learners changes in education, the educator-centered shift to the learner-centered shift, in order to truly realize personalized learning, relying on artificial intelligence technology. The organic integration of modern information technology with artificial intelligence at its core and oral English teaching will revolutionize oral English teaching, provide a personalized oral English teaching platform, and improve students' English application and communication skills. Artificial intelligence technology [15] can be used effectively by junior high school English teachers to conduct oral English evaluation activities, which can more accurately judge students' oral English expression ability and serve as a valuable tool for adjusting and improving students' learning methods.

\section{Related Work}

According to [16], in order to evaluate expression, it is necessary to first intercept the segments of oral testers, then analyze the intercepted contents, and finally obtain features. Learning in oral English evaluation is undergoing a major transformation, according to [17], thanks to the big data analysis method. At the same time, it will raise the value of using a learning system in English and evaluating oral English to a new level. It is no longer just an optional teaching and learning aid, but a capable assistant capable of truly replacing some intelligent human activities. According to [17], English is widely used in Asian countries such as Japan and South Korea for second language learning. In 2004, researchers from Japan's ATR robot laboratory conducted a two-week oral English evaluation teaching experiment with students in grades one and six. The results of the experiment show that Robovie did help some children improve their oral English evaluation level, but it is currently unable to prove the application's rationality [18]. This type of mind map merely replaces the summary of mathematical knowledge points with a different format, and this type of finished mind map cannot have a positive impact on students' thinking ability unless students participate in the mind map creation process. According to the big data analysis method in [19], in traditional oral English evaluation, software for individual learning assistance accounts for the majority, and most of them are not ideal due to their high price and low utilization rate; the other option is to provide online learning assistance via network. They may provide static simulation test papers or have an interactive interface with real-time feedback functions, but they are incapable of being intelligent [20]. At the same time, this teaching method of giving mind maps directly is also a manifestation of neglecting students' dominant position in learning. In this kind of teaching, students are still puppets of teachers, and students' interest and enthusiasm have not been stimulated. In oral English learning, students should have certain information literacy. Reference [21] suggests that many contents of national science, technology, and mathematics courses can be learned. It can be said that it is the most effective way to help curriculum research in oral English evaluation in many fields. There is evidence that it will also have an impact on social skills and help them develop teamwork skills [22]. Through the method of big data analysis, oral English evaluation has penetrated into people's real life at all levels, and it has become a new life concept and lifestyle to use the Internet to improve their own quality and quality of life. Therefore, the online oral English evaluation can realize the automatic management of examination work, greatly shortening the cycle of proposition, test, marking, scoring, and data analysis. A key course in junior high school [23] is artificial intelligence-assisted oral English evaluation, which has a positive impact on students' cross-language communicative competence. As a result, it is critical in English teaching to effectively teach oral English and improve students' oral English levels. The development direction of oral English evaluation, according to [24], is a system that can easily test one's own learning effect and propose targeted improvement measures at different stages, so that not only can the evaluation work be better and faster, but also a lot of time can be saved; the essence of this demand is that the oral English evaluation system provides automatic scoring mechanism and intelligent diagnosis results and analysis.

This paper analyzes the application of artificial intelligence in oral English evaluation. In the process of oral English evaluation, evaluation is a key step. In the teaching 
process, teachers are used to using mind maps to make summaries of chapter contents and then directly show them to students. First of all, students should set speaking learning goals according to their actual needs, identify and screen learning resources suitable for them to learn speaking, listen more, speak boldly, correct pronunciation, learn authentic spoken English, and appreciate the beauty of English language. In education and teaching, mind mapping can be used not only to optimize teaching methods, but also to help students develop logical thinking ability. Moreover, the traditional teaching method means that teachers do not optimize the curriculum teaching in combination with mind map, but simply show the existence of mind map to students and do not deeply think about the different application methods of mind map in the curriculum.

\section{Principle and Model of Intelligent Oral Evaluation}

In the process of learning oral English evaluation, the completion of students' oral preview tasks, the selection and use of oral English evaluation resources, the quality of personal oral expression in oral communication activities, and the completion of after-school review tasks are tracked, recorded, and evaluated by the artificial intelligence technology platform to form corresponding intelligent analysis results. Based on this, teachers make a formative evaluation of students' learning, pay attention to individual differences, suit the remedy to the case, and teach students according to their aptitude. It is our goal to independently write a small ETL tool for the data warehouse system of college English examination and to establish a data mart conveniently and quickly, for learning contents, learning methods, learning evaluation, etc. The goal of English speaking evaluation reform is that students should not only master English knowledge and skills, but also cultivate students' English application ability and autonomous learning ability. This tool simply imports the key data from the database into the database of the data warehouse, and the conversion part will be completed in the data preprocessing of data mining. The flow chart of the spoken English evaluation system ETL is shown in Figure 1.

Figure 1 shows only data extraction and data loading. In order to simplify the system, data conversion is put into data preprocessing. SQL statement refers to extracting data by manually writing SQL statement, and user interface refers to automatically generating SQL statement to extract data through user interface. Under the traditional oral evaluation mode, students carry out formal learning step by step according to the unified deployment of the school, fixed teachers, fixed classrooms, fixed teaching materials, and fixed time. The full house of education, the simplification of learning materials, and the lack of students' classroom participation lead to the disadvantages of students' lack of awareness of English autonomous learning, low autonomous learning ability, and passive learning. The multi-input single output is nonlinear fitting of artificial intelligence, so the modeling method is the neural network with very high fitting accuracy in this aspect, and the artificial intelligence network model is established, as shown in Figure 2.

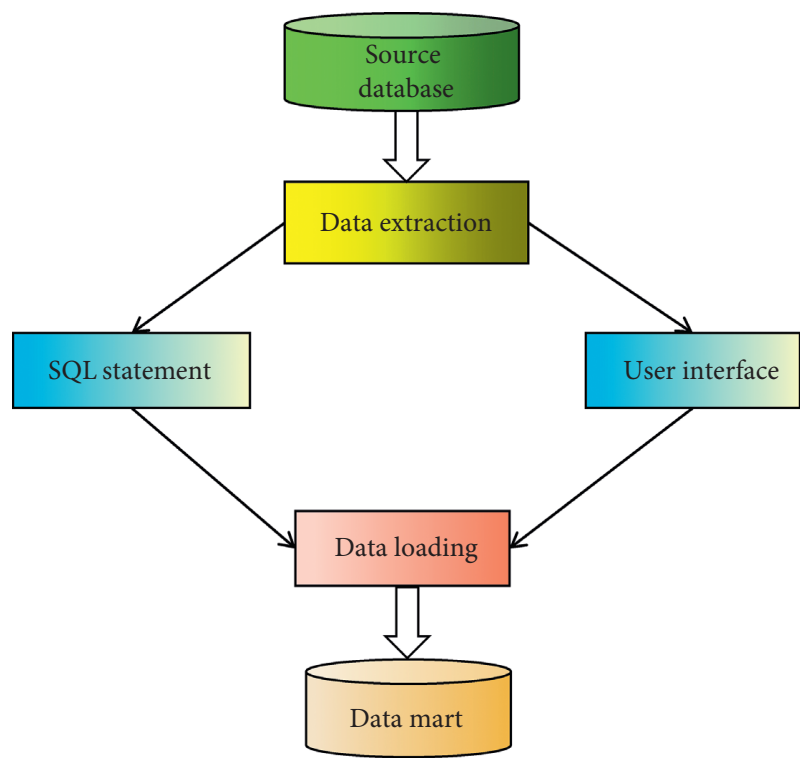

FIgURE 1: Flow chart of ETL.

Selecting test attributes is an important step in artificial intelligence algorithms. Entropy-based metrics attributes that can best classify samples are used by general artificial intelligence algorithms. Teachers can preshow relevant vocabulary and sentence patterns on the online learning platform before the oral English evaluation, allowing students to preview and mark any problems they encounter during the learning process. The number of expected tests to classify an object is reduced using this information theory method. Following is a description of the algorithm. Assume there are $s$ data samples in the set $s$. Define $m$ different $\mathrm{Ci}$ $(I=L, m)$ assuming that the class label attribute has $m$ different values. The number of samples in class $C_{i}$ is given by $\mathrm{Si}$. The following formula calculates the expected information needed to classify a given sample:

$$
I\left(s_{1}, s_{2}, \ldots, s_{m}\right)=-\sum_{i=1}^{m} p_{i} \log _{2}\left(p_{i}\right)
$$

where $P_{i}$ is the probability that any sample belongs to $C_{i}$ and is estimated by $\mathrm{Si} / s$. Note that the logarithmic function is based on 2 because the information is encoded in binary.

Let attribute a have $v$ different values $\left\{A_{1}, A_{2}, \ldots, A_{V}\right\}$. $S$ can be divided into $v$ subsets $\left\{S_{1}, S_{2}, \ldots, S_{V}\right\}$ by attribute a. Among them, $S_{j}$ includes such $\sim$ samples in $s$, which have a value $A_{j}$ on a. Let $\mathrm{S}_{1 j}$ be the number of samples of class $\mathrm{CI}$ in subset $S_{j}$. According to the entropy or expected information divided into subsets by a, it is given by the following formula:

$$
E(A)=\sum_{j=1}^{v} \frac{s_{1 j}+\ldots+s_{m j}}{s} I\left(s_{1 j}, \ldots s_{m j}\right) .
$$

Item $s_{1 j}+\ldots+s_{m j} / s$ acts as the weight of the jth subset and is equal to the number of samples in the subset divided by the total number of samples in $S$. The smaller the entropy, the higher the purity of subset partition. Note that for a given subset $\mathrm{Si}$, 


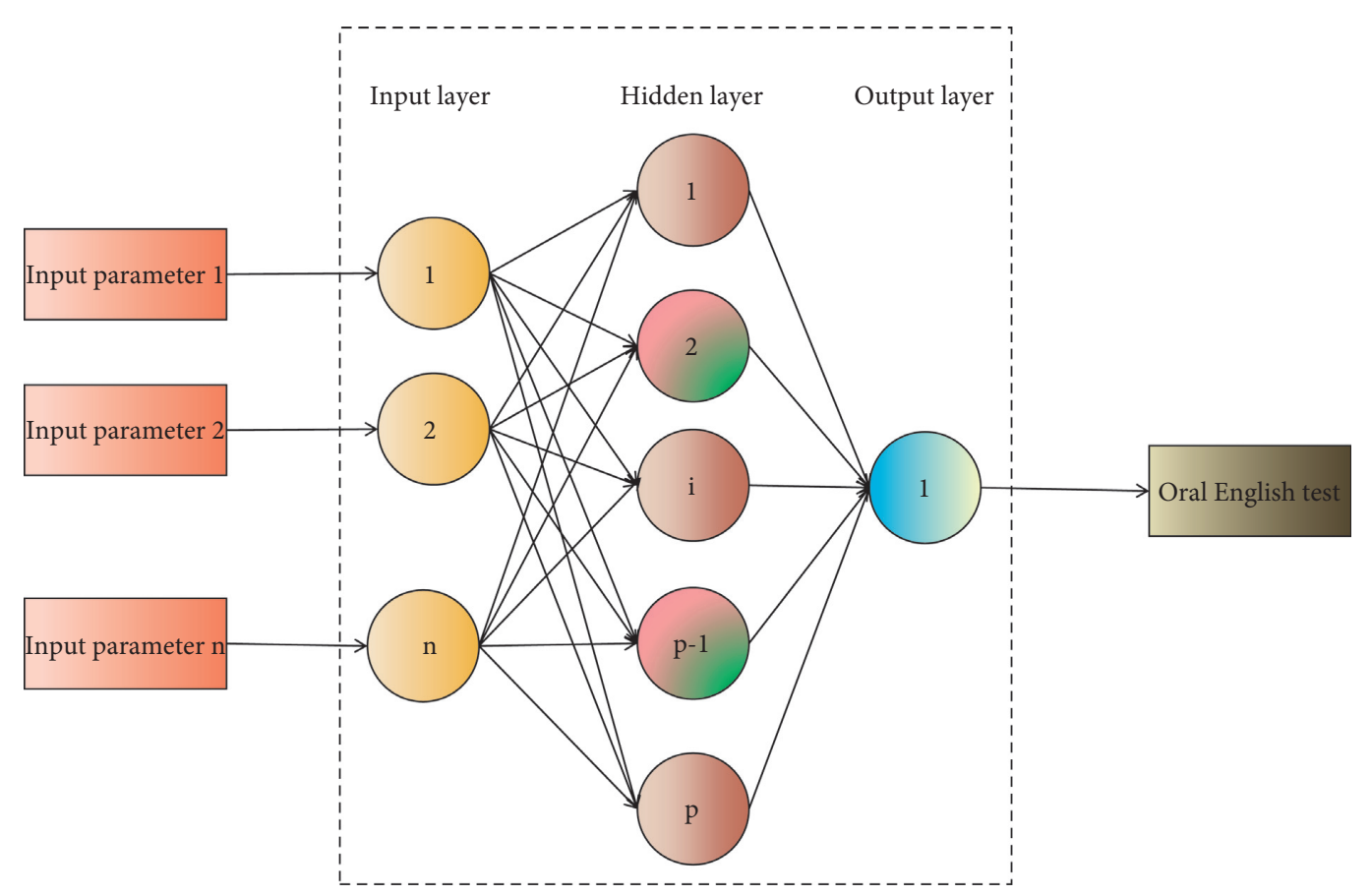

FIGURE 2: Artificial intelligence network model diagram.

$$
I\left(s_{1 j}, s_{2 j}, \ldots, s_{m j}\right)=-\sum_{i=1}^{m} p_{i j} \log _{2}\left(p_{i j}\right),
$$

where $p_{i j}=s_{i j} /\left|s_{j}\right|$ is the probability that the samples in $s j$ belong to class $\mathrm{Ci}$.

The coding information to be obtained by branching on $\mathrm{A}$ is

$$
\operatorname{Gain}(S, A)=I\left(S_{1}, S_{2}, \ldots, S_{m}\right)-E(A) \text {. }
$$

Gain (A) is the expected compression of entropy due to knowing the value of attribute A.

As the test attribute of the given set is S, the attribute with the highest information gain is chosen. Create a node, assign this attribute to it, then create branches for each attribute value, and divide the samples accordingly. Gain has the following drawbacks: it favors attributes with a large number of values and produces a large number of small, pure subsets, such as student ID, name, and date. To reduce the gain in these cases, first calculate the information content of nonclassifiable attributes, i.e., the entropy of $S$ for each value of attribute $\mathrm{A}$.

$$
\operatorname{Splitlnfo}(S, A)=\sum_{m=1}^{v} \frac{s_{m}}{s} \log _{2}\left(\frac{s_{m}}{s}\right),
$$

where $S_{m}$ is the number of samples in attribute A subset and $S$ is the total number of samples. The more the average of the split samples of an attribute by value, the larger the SplitInfo.

The gain ratio uses SplitInfo to avoid selecting these attributes:

$$
\text { GainRation }(S, A)=\frac{\operatorname{Gain}(S, A)}{\operatorname{SplitInfo}(S, A)},
$$

where gain ratio is the gain ratio, gain is the information gain of the attribute, and SplitInfo is the entropy of the attribute.

In terms of expression evaluation, it is necessary to first intercept the oral testers' segments, then analyze the intercepted contents to obtain the characteristics, make a comprehensive evaluation from the perspectives of sound quality, timbre, and tone, and finally summarize to arrive at a reasonable score. The evaluation principle is more complicated for links that require content analysis, such as selfintroduction links. Natural language processing must be used in the evaluation system, and the main operation mode is touch on the front of the display screen. Some smart watches have the crown design of traditional timepieces. Touch input is received through the smart watch's side, frame, strap, and projection, preserving and enhancing the smart watch's shape characteristics while also introducing a new operation mode.

\section{Applied Research in Oral English Evaluation}

4.1. Application Analysis of Artificial Intelligence in Oral English Evaluation. Oral English evaluation under artificial intelligence is a key course in junior high school, which is of positive significance for cultivating students' cross-language communicative competence. Oral English learning and practice are important parts of junior high school English learning. In language communication, middle school students can quickly grasp the learning points and constantly enhance their expression ability. Evaluation is the key step to cultivate students' oral English learning ability. On the basis of evaluation, students can fully understand their own oral English learning level, learning deficiencies, and the next improvement direction. CET-4 and CET-6, which are the 
main means to assess whether Chinese college students' English ability meets the "Teaching Requirements", are also being reformed accordingly. In the past, oral English evaluation mostly relied on teachers' personal experience to judge and score, the evaluation criteria were not scientific and unified enough, and students could not accurately grasp their own pronunciation and expression. In addition, teachers' own teaching ability and professional level were uneven, which would restrict the development of oral English teaching. In the traditional process of oral evaluation, it is mainly to practice oral expression sentence patterns. Teacher-oriented teaching mode of full house irrigation leads to teachers dominating the classroom, performing talk shows alone, passive acceptance by students, less opportunities for participation, and boring classroom atmosphere. With the support of oral English evaluation under artificial intelligence, oral English evaluation in junior middle school can realize real interactive teaching between human and computer and one-to-one teaching guidance between human and computer, which has changed the traditional teacher guidance mode, greatly improved English teaching and learning efficiency, and saved economic cost. This summative evaluation method cannot fully and truly reflect students' oral English level, and it is not conducive to stimulating students' enthusiasm for learning oral English and effectively improving students' comprehensive English level.

The three-dimensional and diversified oral learning resources integrating text, pictures, audio, video, and animation were provided through ubiquitous networks and intelligent terminals; students can break through the restrictions of campus, classroom, classroom and teaching materials; extend oral learning from class to class; integrate online and offline, complement and blend formal learning and informal learning; and truly realize the freedom of time and space. Secondly, the improvement of students' oral English level requires a lot of oral English training in real context. Students can independently choose cooperative, inquiry, gamification, and other learning methods through the artificial intelligence teaching platform and various mobile intelligent terminals. Therefore, in English teaching, it is very important to effectively teach oral English and improve students' oral English level. Therefore, the English Curriculum Standard for Compulsory Education states that students' oral English evaluation ability must be improved. In the diagnosis of English test, if it is only to answer the students, carry out intelligent evaluation through the computer, and finally calculate a score, I believe that such a result will not satisfy both teachers and students, but diagnose immediately after the students submit their answers and give rich and intuitive diagnosis results, which is also an important aspect of intelligent evaluation.

With the support of oral English evaluation under artificial intelligence, oral English evaluation in junior middle school can realize real interactive teaching between human and computer, and one-to-one teaching guidance between human and computer, which has changed the traditional teacher guidance mode, greatly improved English teaching and learning efficiency, and saved economic cost. Junior high school English teachers can effectively use the artificial intelligence technology to carry out oral English evaluation activities, which can judge students' oral English expression ability more accurately, as an important support to adjust and improve students' learning methods. Learning and practicing oral English is an important part of junior high school English. Middle school students can quickly grasp key concepts in language communication and continually improve their ability to express themselves. On the one hand, students' oral English evaluation test scores are an assessment of their learning quality, which can reflect their learning status and knowledge mastery; on the other hand, it also reflects, to some extent, the teaching level and teaching effect of teachers. At the same time, it is linked to employer talent selection, and employers frequently use students' oral English evaluation test scores as a reference. Education entails more than just "knowledge acquisition." What is more important is to develop students' moral character and improve their overall qualities, which are difficult for artificial intelligence to achieve, such as self-confidence, communication, questioning, and sharing. Teachers, on the other hand, can use artificial intelligence as an educational auxiliary tool to better understand students' knowledge. Teachers should also encourage students to evaluate their oral English learning process and outcomes, as well as pay attention to the results of students' self-evaluation. Evaluation is a crucial step in the oral English evaluation process. Teachers are accustomed to using mind maps to create chapter summaries and then showing them to students directly during the teaching process.

4.2. Experimental Results and Analysis. Data mining algorithm, decision tree algorithm, machine learning algorithm, and the method used in this paper are used for experiments, and three oral English evaluation experiments are carried out for comparison. From the dimension lower limit analysis, it can be seen that when artificial intelligence is introduced into oral English evaluation data with enough dimensions, even low correlation parameters can achieve high prediction accuracy. On this basis, this study further analyzes the lower limit of sampling interval accuracy required to maintain modeling accuracy when the dimension of artificial intelligence oral English evaluation data remains unchanged. The research on oral English evaluation can reduce the demand for the amount of oral English evaluation data in their analysis, improve the analysis efficiency, and avoid doubts about the amount of artificial intelligence oral English evaluation data and doubts about the analysis conclusion. The experiments are shown in Figures 3-5, respectively.

The experimental results show that when the sampling interval for oral English evaluation increases gradually, the error of the prediction model increases synchronously and the modeling accuracy decreases gradually, regardless of the difference in relevance or the initial difference. Teachers in traditional classrooms do not focus on the development of 


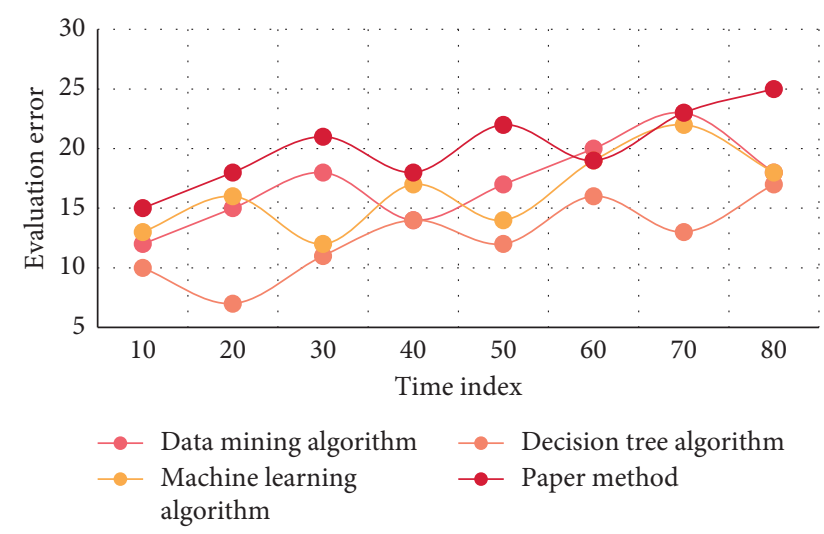

FIGURE 3: Analysis results of artificial intelligence in the lower limit of oral English evaluation (Experiment A).

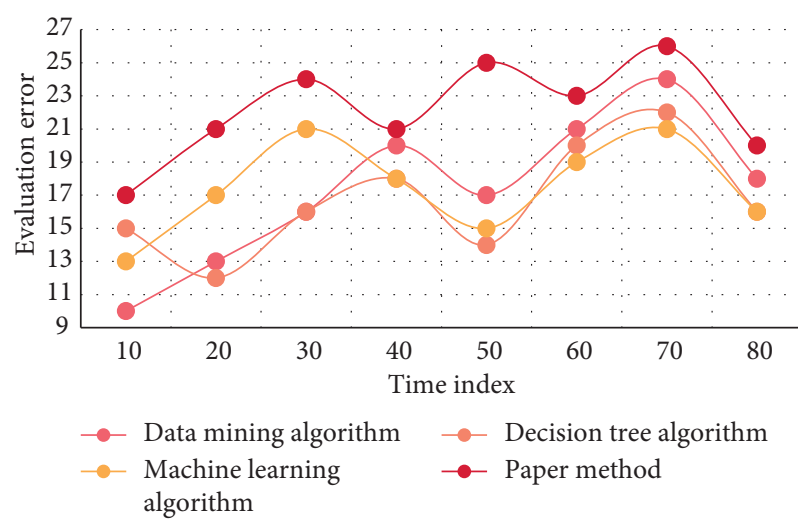

FIgURE 4: Analysis results of artificial intelligence in the lower limit of oral English evaluation (Experiment B).

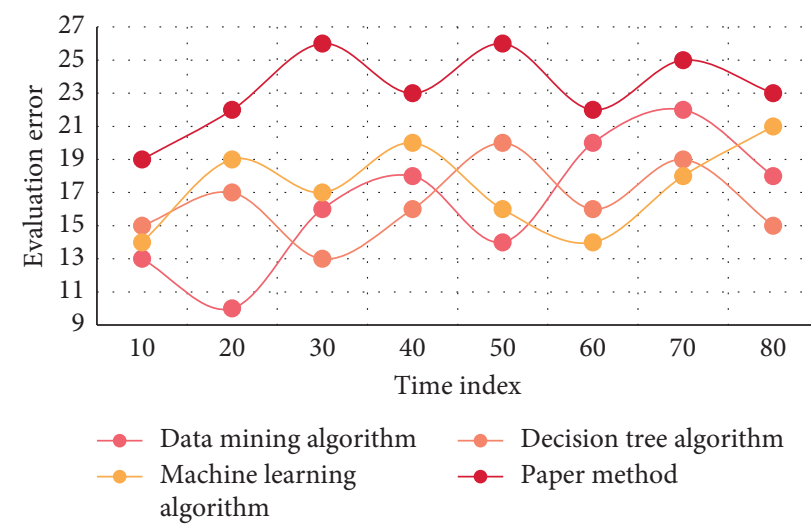

FIgURE 5: Analysis results of artificial intelligence in the lower limit of oral English evaluation (Experiment C).

students' knowledge structures, instead focusing on basic knowledge and problem-solving skills. Junior high school mathematics knowledge, on the other hand, is interconnected, and a strong knowledge structure can aid students in better understanding the relationship and distinctions among mathematics concepts. As a result, teachers should optimize the content they teach and assist students in developing a complete and organized knowledge structure. Teachers can use mind mapping to improve their content delivery. Teachers should be able to organically integrate artificial intelligence technology with oral English evaluation while possessing information technology literacy, use an intelligent network teaching platform to track students' oral English learning behavior, and conduct formative evaluation on students using big data analysis results, in order to achieve online and offline integration of oral English evaluation, which is conducive to reform. Teachers should be able to organically integrate artificial intelligence technology with oral English evaluation while having information technology literacy, use an intelligent online oral English evaluation platform to track students' oral English learning behavior, and conduct formative evaluation on students using big data analysis results, in order to achieve online and offline integration of oral English evaluation, which is conducive to oral English reform.

Artificial intelligence methods are usually divided into categories based on how long they have been around. Estimate the oral English evaluation in the next 10 minutes, half an hour, or one hour in the ultra-short term. The shortterm goal is to estimate the oral English evaluation in the future in a relatively short time frame of one day to one week. The medium term usually refers to the next three months and is calculated in years. The oral English evaluation is estimated to take more than half a year. This study uses a short-term oral English evaluation method. The following sections focus on the simulation process and experiment results. For the purposes of comparison, two experiments are carried out. The experiments are carried out with the help of the decision tree algorithm, the machine learning algorithm, and the method presented in this paper. Figures 6 and 7 depict the results of the experiments.

The experimental results show that, among the three algorithms, the accuracy rate of this method is generally higher than that of the other two algorithms in two experiments. In the teaching process, teachers are used to using mind maps to make summaries of chapter contents and then directly show them to students. This kind of mind map just replaces the summary of mathematical knowledge points with another form, and this kind of finished mind map cannot have a positive impact on students' thinking ability without students' participation in drawing mind map. At the same time, this teaching method of giving mind maps directly is also a manifestation of neglecting students' dominant position in learning. In this kind of teaching, students are still puppets of teachers, and students' interest and enthusiasm have not been stimulated. In oral English learning, students should have certain information literacy, so as to really improve their autonomous learning ability. First of all, students should set speaking learning goals according to their actual needs, identify and screen learning resources suitable for them to learn speaking, listen more, speak boldly, correct pronunciation, learn authentic spoken English, and appreciate the beauty of English language. Secondly, the improvement of students' oral English level requires a lot of oral English training in real context. Students can independently choose cooperative, inquiry, 


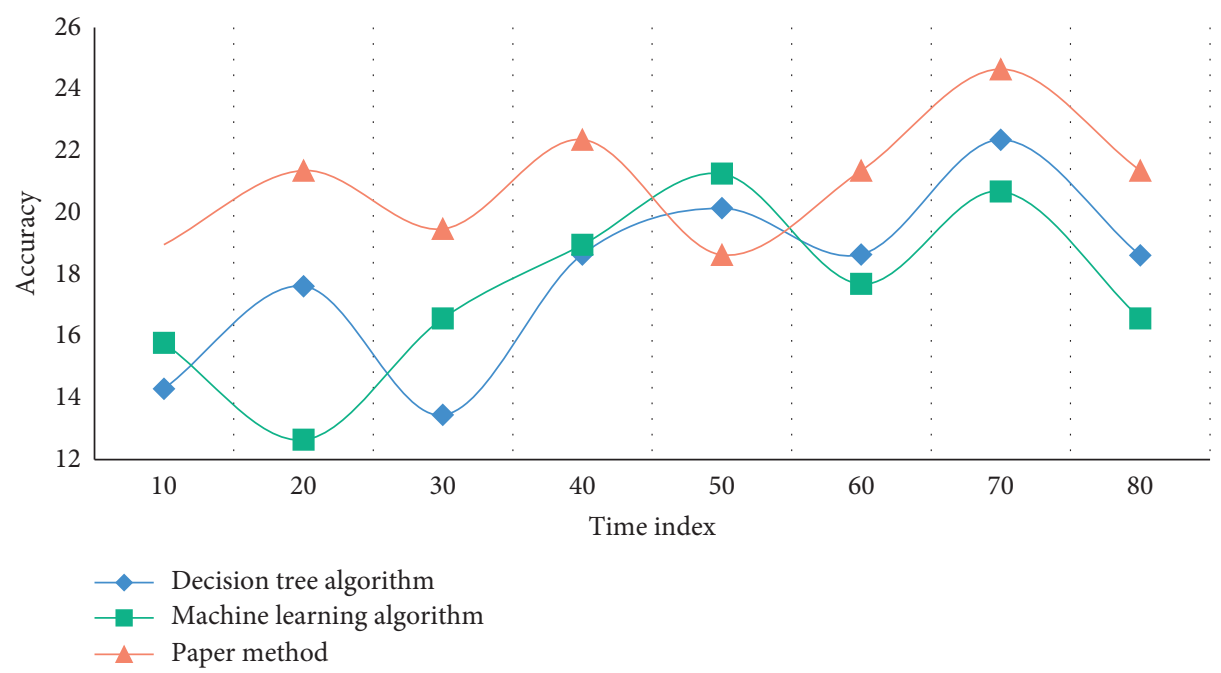

FIGURE 6: Results of the first oral English evaluation.

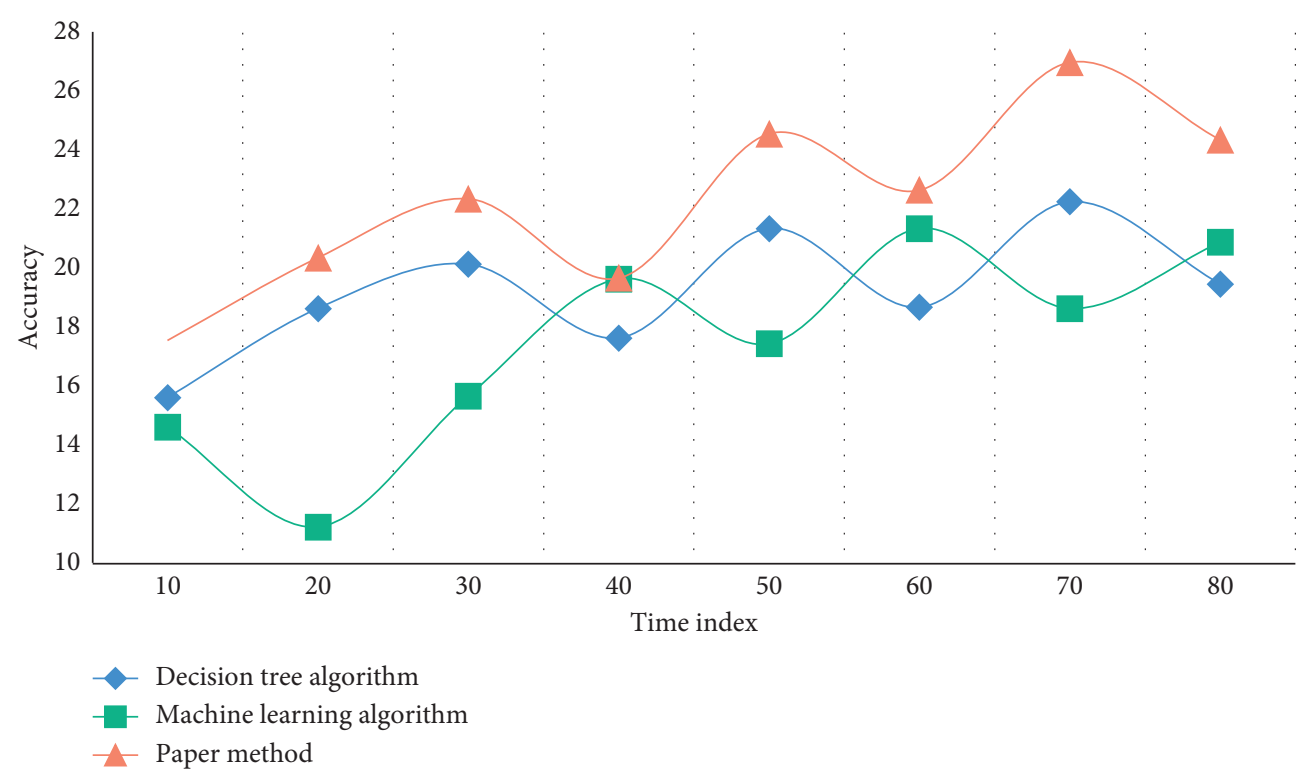

Figure 7: Results of the second oral English evaluation.

gamification, and other learning methods through the artificial intelligence teaching platform and various mobile intelligent terminals.

\section{Conclusions}

Oral English evaluation in the past relied heavily on teachers' personal experience to judge and score, the evaluation criteria were not scientific or unified enough, and students were unable to grasp their own pronunciation and expression accurately. Teachers are no longer the only source of oral English evaluation knowledge in the age of artificial intelligence; they are also the organizer and guide of classroom activities. Teachers should assign teaching tasks to students and assist them in completing them through self-directed learning and group collaboration. The artificial intelligence technology platform tracks, records, and evaluates the completion of students' oral preview tasks, the selection and use of oral English evaluation resources, the quality of personal oral expression in oral communication activities, and the completion of after-school review tasks in the process of learning oral English evaluation. Teachers use this information to formatively assess students' learning, pay attention to individual differences, tailor the remedy to the situation, and teach students based on their aptitude. Teachers can show the relevant vocabulary and sentence patterns on the online learning platform in advance of the oral English evaluation, so students can preview and mark the problems they encounter during the learning process. Teachers and students will be able to communicate more effectively in class, continue the oral class from class to after class, and ensure time for students to practice their oral skills. Teachers are accustomed to using mind maps to 
create chapter summaries and then showing them to students directly during the teaching process.

\section{Data Availability}

The data used to support the findings of this study are included within the article.

\section{Conflicts of Interest}

The authors declare that there are no conflicts of interest.

\section{References}

[1] A. Krp and B. Rs, "Welcome the "new kid on the block" into the family: artificial intelligence in oral and maxillofacial surgery - ScienceDirect," British Journal of Oral and Maxillofacial Surgery, vol. 58, no. 1, pp. 83-84, 2020.

[2] C. Lee, Y. Kim, Y. S. Kim, and J. Jang, "Automatic disease annotation from radiology reports using artificial intelligence implemented by a recurrent neural network," American Journal of Roentgenology, pp. 1-7, 2019.

[3] J. Murphy, "Artificial intelligence, rationality, and the world wide web," IEEE Intelligent Systems, vol. 33, no. 1, pp. 98-103, 2018.

[4] S. Russell, "Artificial intelligence: the future is superintelligent,” Nature, vol. 548, no. 7669, pp. 520-521, 2017.

[5] D. Milojicic, "Accelerators for artificial intelligence and highperformance computing," Computer, vol. 53, no. 2, pp. 14-22, 2020.

[6] N. Nosengo, "Can artificial intelligence create the next wonder material?" Nature, vol. 533, no. 7601, pp. 22-25, 2016.

[7] S. M. Jaleh, Z. Hojjat, S. N. Fatemeh, S. Reza, and D. S. Azimeh, "Neonatal intensive care decision support systems using artificial intelligence techniques: a systematic review," Artificial Intelligence Review, vol. 52, no. 4, pp. 2685-2704, 2019.

[8] M. Mossio and L. Bich, "What makes biological organisation teleological?” Synthese, vol. 194, no. 4, pp. 1-26, 2017.

[9] G. Karakaya and M. Koksalan, "An interactive approach for Bi-attribute multi-item auctions," Annals of Operations Research, vol. 245, no. 1-2, pp. 1-23, 2016.

[10] L. Chen, Y. Feng, S. Huang, B. Luo, and D. Zhao, "Encoding implicit relation requirements for relation extraction: a joint inference approach," Artificial Intelligence, vol. 265, pp. 4566, 2018.

[11] T. Flati, D. Vannella, T. Pasini, and R. Navigli, "MultiWiBi: the multilingual Wikipedia bitaxonomy project," Artificial Intelligence, vol. 241, pp. 66-102, 2016.

[12] S. O. Alhumoud and A. A. Wazrah, "Arabic sentiment analysis using recurrent neural networks: a review," Artificial Intelligence Review, pp. 1-42, 2021.

[13] I. Ito, A. Ito, and S. Unezaki, "Investigation of oral preparation that is expected to improve medication administration: preparation and evaluation of oral gelling tablet using sodium alginate," Yakugaku Zasshi, vol. 137, no. 8, pp. 969-977, 2017.

[14] G. Mutsa, P. Bonny, C. Henry, N. Gauld, and V. Mumford, "Is reclassification of the oral contraceptive pill from prescription to pharmacist-only cost effective? Application of an economic evaluation approach to regulatory decisions," PharmacoEconomics, vol. 37, no. 8, pp. 1049-1064, 2019.

[15] J. Kong, H. Wang, X. Wang, X. Jin, X. Fang, and S. Lin, "Multi-stream hybrid architecture based on cross-level fusion strategy for fine-grained crop species recognition in precision agriculture," Computers and Electronics in Agriculture, vol. 185, Article ID 106134, 2021.

[16] K. Rupel, M. Tettamanti, F. Vella et al., "What do we learn from the clinical and biological evaluation of the oral cavity in centenarians?" Maturitas, vol. 145, no. 3, pp. 31-37, 2021.

[17] R. H. Six, T. Geurden, R. Packianathan et al., "Evaluation of the effectiveness of a novel oral formulation of sarolaner (Simparica) for the treatment and control of fleas on dogs," Veterinary Parasitology, vol. 222, no. 6, pp. 18-22, 2016.

[18] A. Ninfa, N. Pizzorni, A. Eplite, C. Moltisanti, and A. Schindler, "Validation of the Italian version of the functional oral intake scale (FOIS-it) against fiberoptic endoscopic evaluation of swallowing and nutritional status," Dysphagia, pp. 1-11, 2021.

[19] J. Chhatwal, T. He, and M. A. Lopez-Olivo, "Systematic review of modelling approaches for the cost effectiveness of hepatitis C treatment with direct-acting antivirals," PharmacoEconomics, vol. 34, no. 6, pp. 551-567, 2016.

[20] K. Bertl, I. Steiner, N. Pandis, K. Buhlin, B. Klinge, and A. Stavropoulos, "Statins in nonsurgical and surgical periodontal therapy. A systematic review and meta-analysis of preclinical in vivo trials," Journal of Periodontal Research, vol. 53, no. 3, pp. 267-287, 2018.

[21] Z. Siliang, X. Qiming, X. Shuqing et al., "The association between urate-lowering therapies and treatment-related adverse events, liver damage, and major adverse cardiovascular events (MACE): a network meta-analysis of randomized trials," Pharmacotherapy: The Journal of Human Pharmacology and Drug Therapy, vol. 41, no. 9, pp. 781-791, 2021.

[22] L. Xu, B. Cai, and Z. Fang, "Translation and validation of a Chinese version of the mandibular function impairment questionnaire," Journal of Oral Rehabilitation, vol. 43, no. 8, pp. 608-614, 2016.

[23] S. Perez, O. Tatar, R. Ostini et al., "Extending and validating a human papillomavirus (HPV) knowledge measure in a national sample of Canadian parents of boys," Preventive Medicine, vol. 91, pp. 43-49, 2016.

[24] Y. Chen, J. L. Shergis, L. Wu et al., "A systematic review and meta-analysis of the herbal formula Buzhong Yiqi Tang for stable chronic obstructive pulmonary disease," Complementary Therapies in Medicine, vol. 29, pp. 94-108, 2016. 